\title{
Modelling of Demand Driven Biogas Plants to Cover Residual Load Rises ${ }^{+}$
}

\author{
Lena Peters *, Piotr Biernacki, Frank Uhlenhut and Sven Steinigeweg \\ Department of Technology, University of Applied Sciences Emden/Leer, 26723 Emden, Germany; \\ piotr.biernacki@hs-emden-leer.de (P.B.); frank.uhlenhut@hs-emden-leer.de (F.U.); \\ sven.steinigeweg@hs-emden-leer.de (S.S.) \\ * Correspondence: lena.peters@hs-emden-leer.de; Tel.: +49-4921-807-1459 \\ + Presented at the Economy, Sustainable Development and Energy International Conference (ESDEIC), \\ Edinburgh, Scotland, UK, 25-27 June 2018.
}

Published: 31 October 2018

\begin{abstract}
In future, systems for energy storage and demand-driven energy production will be essential to cover the residual load rises. A rigorous dynamic process model based on ADM1 was used to analyze the flexible operation of biogas plants for covering the residual load rises. This model was optimized and an operation concept for a demand-driven energy production was worked out. For the input data different substrates were analyzed by batch fermentations and the Weender analysis with van Soest method. The results show that the substrates have got a different biogas production rate and reaction time. Finally, an intelligent feeding algorithm by implementation of a PI controller was developed. It calculates feeding times and quantities of available substrates so that a defined energy demand can be covered by biogas plants. The results demonstrate that a flexible operation of biogas plants with an individual and intelligent feeding program is possible.
\end{abstract}

Keywords: biogas; demand-driven biogas production; energy storage; flexibilisation

\section{Introduction}

Limited fossil resources and the climate change require a more efficient and environmentally friendly energy production. Hence, the energy policy concept of Germany provides that in future the electricity will be mostly covered by renewable energies. Because wind and solar energy sources depend on climate conditions, fluctuations in energy supply will occur [1]. Energy storage systems and systems for demand-driven energy production will be essential to cover the residual load rises. Hence, different strategies for flexibilisation of biogas plants are currently being investigated. These include concepts like feeding management, disintegration and storage of intermediates, increase of the capacity of gas storages and CHP units, treatment to biomethane, and further adapted plant configurations like Power-to-Gas or Power-to-Heat [1,2].

Within the project "Flexibla" at the University of Applied Sciences Emden/Leer, the flexibilisation was realised by a feeding management. A rigorous dynamic process model in MATLAB, based on the Anaerobic Digestion Model No. 1 (ADM1), was used to analyze the flexible operation of biogas plants for covering the residual load rises [3]. This model was optimized and an operation strategy, that makes a demand-driven energy production possible, was devised. For this, an intelligent feeding algorithm was developed by the implementation of a PI controller which adapts the feeding times and quantities to the energy demand. Actually, there are lab experiments for a flexible feeding of biogas plants [4] and a few methodologies for substrate feed control, too [5]. But there is no fully developed control model for a completely flexible feeding of industrial biogas plants to cover a fluctuating load profile of energy, based on ADM1 and PI controller. 


\section{Materials and Methods}

For analyzing a flexible operation of biogas plants a rigorous dynamic process model based on ADM1xp was created and optimized. Moreover an operation concept for a demand-driven energy production was developed. For that the feeding times and quantities of available substrates were adapted to the energy demand by the implementation of a PI controller. Using batch experiments and the Weender analysis with van Soest method, the ingredients and degradation kinetics of different substrates were examined to identify necessary model parameters. Finally, an optimum feeding strategy was determined.

\subsection{Substrate Analysis}

By batch experiments and the Weender analysis with van Soest method, different substrates which can be used for biogas production were characterized. For example maize silage, rye, triticale, sugar beets, potato pieces, as well as potato peels belong to these substrates. The batch experiments served for the examination of the degradation kinetics and biogas production rate, and were done by the gas pressure system of Ankom ${ }^{\circledR}$. By the Weender analysis different ingredients of the substrates (e.g., proteins, carbohydrates and lipids) were determined. These measurements were necessary to calculate the input parameters of the process model for the different substrates.

\subsection{Process Model and Feeding Algorithm}

The used process model for biogas plants, called ADM1xp, is based on the ADM1 [3,6]. In MATLAB, this model was optimized by implementation of further fractions like ammonia in the gas phase (according to Zhang [7]) and lactic acid in the liquid phase (according to Satpathy [8]). Furthermore, the determined input data for the different substrates from chapter 2.1 were implemented into the model. The results of the batch experiments served for the calibration of the model. Moreover an operation concept was established that enables the production of biogas or energy when it is needed. For that, an intelligent feeding algorithm based on a PI controller was developed. The controller reads in a profile of methane demand and adapts the necessary feeding times and quantities of substrate.

\subsection{Flexible Feeding of Lab Biogas Plant}

The feasibility of flexible feeding was tested at a $25 \mathrm{~L}$ lab biogas plant, especially regarding to process stability and biogas production. At this plant a daily pattern feeding with only one feeding of maize silage each day was tested. Additionally, a seven liter plant, which was operated continuously, supplied reference values.

\section{Results}

\subsection{Substrate Analysis}

The analyzed biogas production rates and biogas amounts of the different substrates are shown in Figure 1. The results of the Weender analysis with van Soest extension were used to calculate the input data for the process modelling according to the equations of Koch [9].

\subsection{Flexible Feeding of Lab Biogas Plant}

The biogas production by a flexible, daily pattern feeding at the lab biogas plant with one feeding each day caused also one peak at each day. During this experiment, the fermentation process remained stable. So it could be shown that such a flexible feeding is possible to produce daily peaks in biogas production. 


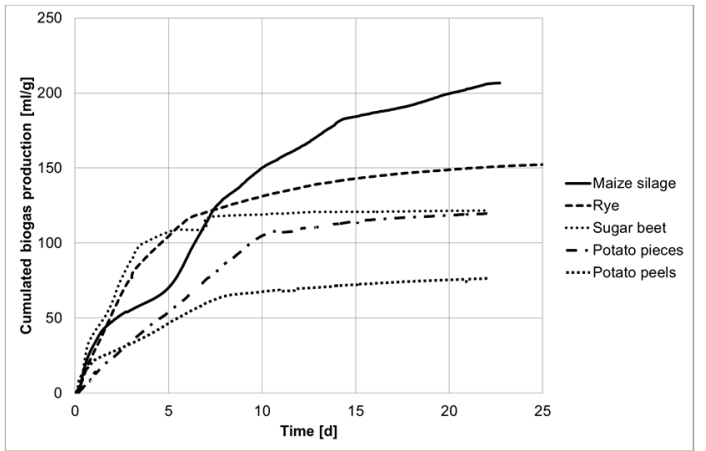

(a)

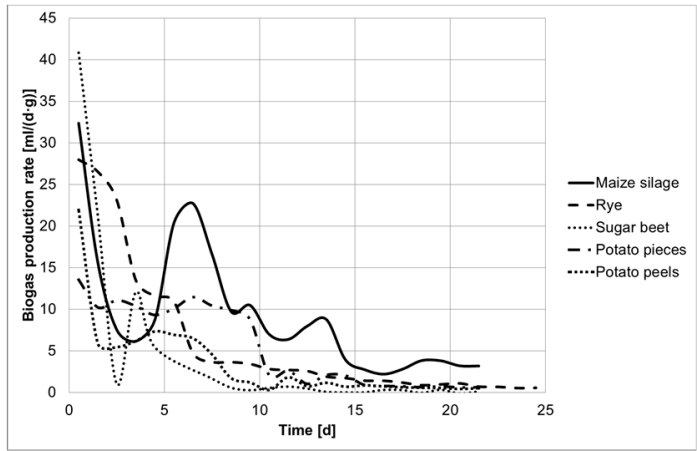

(b)

Figure 1. Biogas production within batch fermentation for different substrates (maize silage, rye, sugar beet, potato pieces and peels) (a) Cumulated biogas production in ml biogas per gram substrate;

(b) Biogas production rate in $\mathrm{ml}$ biogas per day and gram substrate.

\subsection{Process Modelling}

With the process model it is calculated how a flexible operation of biogas plants can be used to cover an exemplary profile of residual load rise. The controller within the model determines the feeding times and amounts of available substrates so that the given energy demand can be covered by the power production of a biogas plant as best as possible. Then the methane demand can be compared with the methane production by the model. The comparison of the simulated methane production with the methane demand shows that $75.6 \%$ of the demand with regard to the time can be at least covered, whereby more methane is often produced than is required. During the remaining $24.4 \%$ there is an underproduction. However, the overproduced methane can be intermediately stored and used to supply the left energy demand during the phase of underproduction. Maximum deviations between methane demand and production of almost $3000 \mathrm{~m}^{3}$ methane per day were observed. These high deviations are caused by a shift between the peaks of demand and production, due to the slowness of the biogas process.

\section{Discussion}

The results of substrate analysis show that maize silage has the highest cumulated biogas production after 21 days, followed by rye, sugar beet, and at last the potato pieces and peels. However, sugar beet is fastest degraded at the first day. So it produces very quickly biogas which is important for the flexible feeding, because a rapid reaction to fluctuations of power demand will be necessary.

The comparison of methane demand and production after controlling shows that the feeding controller is working in any case. However, the curves also demonstrate the slowness of the biogas process, because the peaks of the model appear a little bit later than the peaks of the demand curve. Here, an optimization of the model and controller parameters could improve the results. Anyway, to cover the remaining energy demand, combinations of different flexibilisation concepts (e.g., gas storage strategies) are always possible and probably necessary as well.

\section{Conclusions}

The results show that the selected substrates have got a different biogas production rate and reaction time. Maize silage has the highest biogas production but sugar beet is faster degraded.

A possible flexible feeding was shown by a daily pattern feeding at a lab scale reactor, which can produce one peak in biogas production at each day while the process remains stable.

It is also shown that it could be possible to cover the residual load rises with an intelligent feeding of a biogas plant by simulation in MATLAB with the ADM1xp model. A PI controller adapts the feeding times and substrate quantities so that the given energy demand can be covered by the power production of a biogas plant as best as possible. According to the substrate feeding, a contemporary increase of the gas amount could be reached. Nevertheless, there are differences left 
between methane production and demand due to the slow biogas process. Probably, further optimizations of the model and control parameters could improve the results. However, a combination of different flexibilisation concepts will always be possible to cover missing production. All in all, the results show that it is possible to operate biogas plants flexibly with an individual and intelligent feeding program.

Author Contributions: L.P. developed the process model, performed the lab experiments and the simulations, analyzed the data and wrote the paper. P.B. and F.U. supported the design of experiments, mentored L.P. and proofread the paper. S.S. managed the project and proofread the paper.

Acknowledgments: The authors would like to thank the European Regional Development Fund (ERDF) for the financial support within the research project "Flexibla-Flexible operation of biogas and biomethane plants".

Conflicts of Interest: The authors declare no conflict of interest.

\section{References}

1. Hahn, H.; Krautkremer, B.; Hartmann, K.; Wachendorf, M. Review of concepts for a demand-driven biogas supply for flexible power generation. Renew. Sustain. Energy Rev. 2014, 29, 383-393, doi:10.1016/j.rser.2013.08.085.

2. Peters, L.; Uhlenhut, F.; Biernacki, P.; Steinigeweg, S. Status of demand-driven biogas concepts to cover residual load rises. ChemBioEng Rev. 2018, 5, 163-172, doi:10.1002/cben.201800004.

3. Batstone, D.J.; Keller, J.; Angelidaki, I.; Kalyuzhnyi, S.V.; Pavlostathis, S.G.; Rozzi, A.; Sanders, W.T.M.; Siegrist, H.; Vavilin, V.A. Anaerobic Digestion Model No. 1-IWA Task Group for Mathematical Modelling of Anaerobic Digestion Processes; IWA Publishing: London, UK, 2002.

4. Mauky, E.; Weinrich, S.; Jacobi, H.F.; Nägele, H.J.; Liebetrau, J.; Nelles, M. Demand-driven biogas production by flexible feeding in full-scale-Process stability and flexibility potentials. Anaerobe 2017, 46, 86-95, doi:10.1016/j.anaerobe.2017.03.010.

5. Mauky, E.; Weinrich, S.; Nägele, H.J.; Jacobi, H.F.; Liebetrau, J.; Nelles, M. Model predictive control for demand-driven biogas production in fullscale. Chem. Eng. Technol. 2016, 39, 652-664, doi:10.1002/ceat.201500412.

6. Wett, B.; Eladawy, A.; Ogurek, M. Description of nitrogen incorporation and release in ADM1. Water Sci. Technol. 2006, 54, 67-76, doi:10.2166/wst.2006.527.

7. Zhang, Y.; Piccard, S.; Zhou, W. Improved ADM1 model for anaerobic digestion process considering physico-chemical reactions. Bioresour. Technol. 2015, 196, 279-289, doi:10.1016/j.biortech.2015.07.065.

8. Satpathy, P.; Biernacki, P.; Uhlenhut, F.; Cypionka, H.; Steinigeweg, S. Modelling anaerobic digestion in a biogas reactor: ADM1 model development with lactate as parameter (Part I). J. Environ. Sci. Health A 2016, 51, 1216-1225, doi:10.1080/10934529.2016.1212558.

9. Koch, K.; Lübken, M.; Gehring, T.; Wichern, M.; Horn, H. Biogas from grass silage-Measurements and modeling with ADM1. Bioresour. Technol. 2010, 101, 8158-8165, doi:10.1016/j.biortech.2010.06.009. 